\title{
Lipase degradation of plasticized polyvinyl chloride endotracheal tube surfaces to create nanoscale features
}

This article was published in the following Dove Press journal:

International Journal of Nanomedicine

16 March 2017

Number of times this article has been viewed

\author{
Mary C Machado' \\ Thomas J Webster ${ }^{2}$ \\ 'Center for Biomedical Engineering, \\ Division of Engineering Brown \\ University, Providence, RI, \\ ${ }^{2}$ Department of Chemical Engineering, \\ Northeastern University, Boston, \\ MA, USA
}

Video abstract

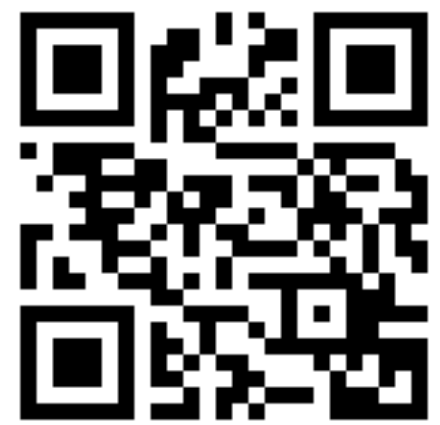

Point your SmartPhone at the code above. If you have a QR code reader the video abstract will appear. Or use-

http://youtu.be/vUnf-PqbvF4

Correspondence: Thomas J Webster Department of Chemical Engineering, Northeastern University, 360 Huntington Avenue, Boston, MA 027I5, USA

$\mathrm{Tel}+\mathrm{I} 6173736585$

Email th.webster@neu.edu
Abstract: Polyvinyl chloride (PVC) endotracheal tubes (ETTs) nanoetched with a fungal lipase have been shown to reduce bacterial growth and biofilm formation and could be an inexpensive solution to the complex problem of ventilator-associated pneumonia (VAP). Although bacterial growth and colonization on these nanoetched materials have been well characterized, little is known about the mechanism by which the fungal lipase degrades the PVC and, thus, alters its properties to minimize bacteria functions. This study used X-ray photoelectron spectroscopy (XPS) and attenuated total reflectance Fourier transform infrared spectroscopy (ATR-FTIR) to better describe the surface chemistry of both unetched and lipase nanoetched PVC ETT. ATR-FTIR analysis of the unetched and treated surfaces showed a similar presence of a plasticizer. This was confirmed by XPS analysis, which showed an increase of carbon and the presence of oxygen on both unetched and nanoetched surfaces. A quantitative comparison of the FTIR spectra revealed significant correlations (Pearson's correlation, $R=0.997\left[R^{2}=0.994\right.$, $P<0.001]$ ) between the unetched and nanomodified PVC ETT spectra, demonstrating similar surface chemistry. This analysis showed no shifting or widening of the bands in the spectra and no significant changes in the intensity of the infrared peaks due to the degradation of the plasticizer by the fungal lipase. In contrast, results from this study did demonstrate significantly increased nanoscale surface features on the lipase etched compared to non-etched PVC ETTs. This led to a change in surface energetics, which altered ion adsorption to the ETTs. Thus, these results showed that PVC surfaces nanoetched with a $0.1 \%$ lipase solution for 48 hours have no significant change on surface chemistry but do significantly increase nanoscale surface roughness and alters ion adsorption, which suggests that the unique properties of these materials, including their previously reported ability to decrease bacterial adhesion and growth, are due to the changes in the degree of the nanoscale roughness, not changes in their surface chemistry.

Keywords: nanorough, lipase, hydrolysis, spectroscopy, polymer

\section{Introduction}

Endotracheal tubes (ETTs) are frequently used in clinical settings with 20 million intubations performed annually. ${ }^{1}$ Device-associated infections such as ventilatorassociated pneumonia (VAP) are closely associated with these tubes and not only affect the health of patients ${ }^{2-6}$ but can also increase healthcare costs by as much as US\$55,882 per patient. . $^{7}$

Thus, the development of ETT surfaces resistant to bacterial growth and colonization is a pressing concern. ETTs used today are composed primarily of polyvinyl chloride (PVC) combined with a plasticizer, usually an organic acid ester, to increase the flexibility of the material..$^{9}$ Plasticized polyvinyl chloride (pPVC) tubes with 
nanomodified surfaces (or surfaces with features $<100 \mathrm{~nm}$ in one direction) could reduce bacterial adhesion and biofilm formation at the surface of ETTs. Surfaces with nanoscale features, such as nanoetched pPVC, mimic the natural dimensions of the cells and tissues within the body and have unique surface energetics (due to the increased surface area and, thus, exposure of the ETT chemistry). ${ }^{10}$ These surfaces have also been shown to attract the adsorption of proteins known to reduce bacteria attachment. ${ }^{11,12}$ Furthermore, pPVC ETT surfaces nanoetched with the fungal lipase Rhizopus arrhizus have been shown to significantly reduce the growth of Staphylococcus aureus and Pseudomonas aeruginosa (log reductions of 1.65 and 1.53 , respectively), two of the most common bacteria found in VAP. ${ }^{2}$

Although the unique antimicrobial properties of $\mathrm{pPVC}$ etched with $R$. arrhizus are well characterized, the mechanism for the creation of these nanoetched surfaces remains unclear. The nanomodification of polymer surfaces using bacterial and fungal lipases is not well described within the literature. Fortunately, degradation of polymers such as pPVC by microbes is a well-known phenomenon and has been studied extensively. ${ }^{13-16}$ Fungi have been shown to degrade esterbased plasticizers such as pPVC. ${ }^{17}$ Biodegradation by fungi has been attributed to sn-1,3-specific lipases, such as the lipase found in Rhizopus arrhizus. These lipases have been shown to degrade polyesters and phthalates, specifically di(2-ethylhexyl) phthalate. ${ }^{13,16-18}$
Studies on the biodegradation of phthalates in the presence of microorganisms have shown that the mechanism of this reaction is a sequential hydrolysis of each ester-alkyl chain. ${ }^{19}$ Thus, this study proposes the following mechanism, shown in Figure 1, for the hydrolysis of the plasticizer in pPVC by the fungal lipase $R$. arrhizus.

A more accurate analysis of the surface chemistry of the nanoetched material could lead to an increased insight into the mechanism of the lipase etching of pPVC and finally to a better understanding of the interaction of $S$. aureus and $P$. aeruginosa with the ETT surface. Therefore, the objective of this study is to confirm the lipase-catalyzed change at the surface of pPVC using both X-ray photoelectron spectroscopy (XPS) and Fourier transform infrared spectroscopy (FTIR) analysis.

\section{Methods}

\section{Preparation of nanomodified ETT}

Sheridan ${ }^{\circledR}$ PVC ETTs (Hudson RIC, Temecula, CA, USA) were modified using a fungal lipase produced from $R$. arrhizus (Sigma Aldrich, St Louis, MO, USA). PVC ETTs were cut into pieces with a length of $0.6 \mathrm{~cm}$ and a width of $0.3 \mathrm{~cm}$. PVC pieces were then immersed in $20 \mathrm{~mL}$ of a $0.1 \%$ mass solution of $R$. arrhizus lipase dissolved in a $1 \mathrm{M}$ potassium phosphate buffer (Fisher Scientific, Waltham, MA, USA). These pieces were then gently agitated on an incubator shaker (Excella E24, New Brunswick Scientific, Edison, NJ, USA)

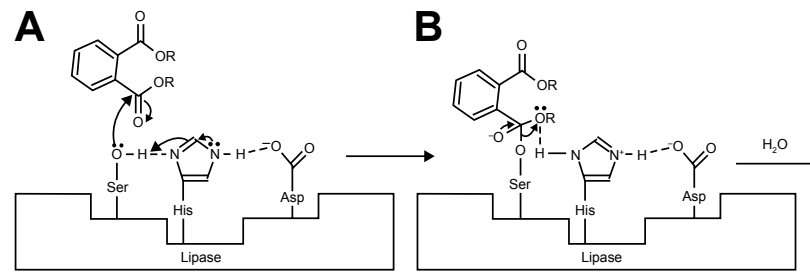

$\mathbf{E}$

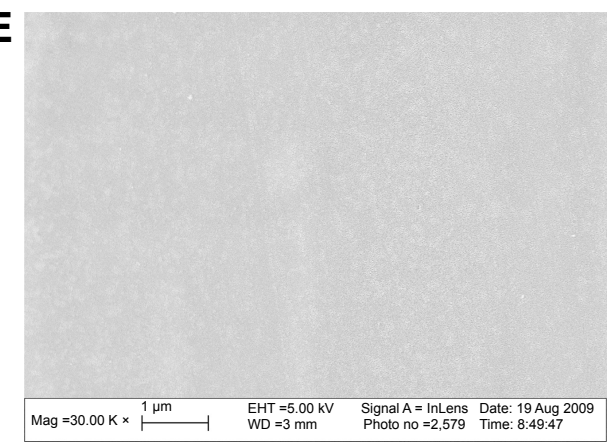

C

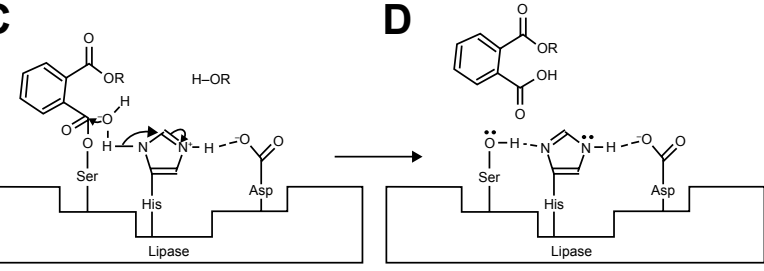

$\mathbf{F}$

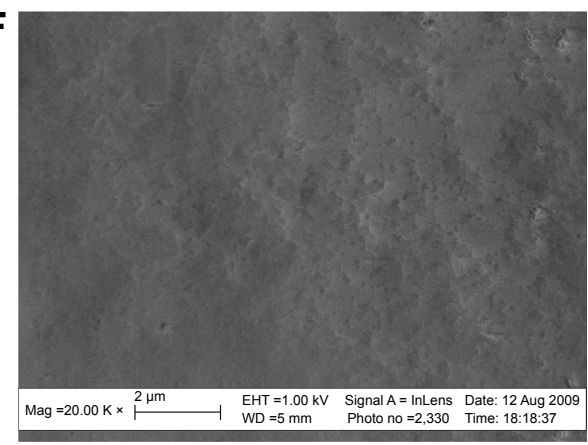

Figure I Proposed mechanism for hydrolysis of a plasticizer by Rhizopus arrhizus lipase.

Notes: (A) Phthalate binds to the lipase molecule and the active site of the lipid (Ser $\left.\mathrm{O}^{-}\right)$and performs a nucleophilic attack of the substrate's carbonyl carbon atom. (B) A transition state occurs where a covalent intermediate is formed by binding of the substrate to the enzyme's serine residue. (C) A water molecule is activated by the histidine residue of the lipase and performs a nucleophilic attack on the intermediate. (D) The products of the reaction are released. (E) SEM image of unetched PVC ETT: magnification $\times 30 \mathrm{~K}$. (F) SEM image of PVC ETT etched with a $0.1 \%$ R. arrhizus solution (nano-R): magnification $\times 20 \mathrm{~K}$.

Abbreviations: ETT, endotracheal tube; PVC, polyvinyl chloride; SEM, scanning electron microscopy. 
for 24 hours at $37^{\circ} \mathrm{C}$ and $200 \mathrm{rpm}$. After 24 hours, the lipase solution was replaced and the ETT pieces were agitated for an additional 24 hours. At the end of 48 hours, the ETT pieces were removed from the lipase solution and were washed with distilled water. The ETT pieces were then sterilized using ethylene oxide exposure (Steri-Vac 5XL, 3M, Minneapolis, MN, USA) in a 16-hour sterilization cycle.

The activity of the $R$. arrhizus lipase used in this experiment was $10.5 \mathrm{U} / \mathrm{g}$, where one unit is defined as the amount of enzyme that catalyzes the release of $1 \mu \mathrm{mol}$ of oleic acid per minute at $\mathrm{pH} 7.4$ and $40^{\circ} \mathrm{C} .^{20}$

\section{Surface analysis}

To compare the surface chemistry of the nanomodified samples to the unmodified samples, attenuated total reflectance FTIR (ATR-FTIR) was used. Two untreated pPVC sections and two nanomodified sections were evaluated using ATR-FTIR. Briefly, in situ surface structural changes were observed using a Vertex 70 spectrometer (Bruker Optik GmbH, Ettlingen, Germany) equipped with a ZnSe crystal (path length of $1.66 \mu \mathrm{m})$ and OPUS 6.5 software (Bruker Optik GmbH). Samples were observed at ambient temperature and at a resolution of $4 \mathrm{~cm}^{-1}$. Background spectra were subtracted from the obtained reflectance. Bands in the FTIR spectra obtained in this analysis were then compared with standards to determine any differences in the chemical composition of the samples.

Additional tests were conducted to determine ion absorption on the material surface from the cell culture media. Nanomodified and unmodified PVC samples were soaked in tryptic soy broth (TSB) media for 24 hours at $37^{\circ} \mathrm{C}$, rinsed with deionized, sterilized water, and air dried. The surfaces of each sample were characterized using XPS. The XPS samples were processed using a 5500 Multitechnique Surface Analyzer (Perkin Elmer, Waltham, MA, USA) with an Al K-alpha monochromatized X-ray source. Each surface was analyzed in an annular area of $400 \mu \mathrm{m}$. Acquired data were processed with appropriate software (PC Access ESCA V7.2C, Physical Electronics, Chanhassen, MN, USA) and compared with un-soaked samples.

\section{Statistics}

To measure similarity between spectra, spectra were analyzed using the Pearson's product moment correlation coefficient. For each pair of untreated and nanomodified samples, Pearson's product moment correlation coefficients were assessed between each replicate using SPSS statistics software (IBM, Armonk, NY, USA) and then averaged. Correlation coefficients were calculated for the entire IR spectra and for relevant zones of the IR spectrum described as follows: 3,700-3,200, 3,200-2,700, 2,000-1,680, $1,680-1,450 \mathrm{~cm}^{-1}$, and the fingerprint region. Similarity indices, such as the squared correlation coefficient, were also calculated for each of these regions. Spectral similarity was considered significant at $P<0.05$.

\section{Results}

The ATR-FTIR spectra of both the unmodified and nanomodified surfaces are shown in Figure 2. PVC can be
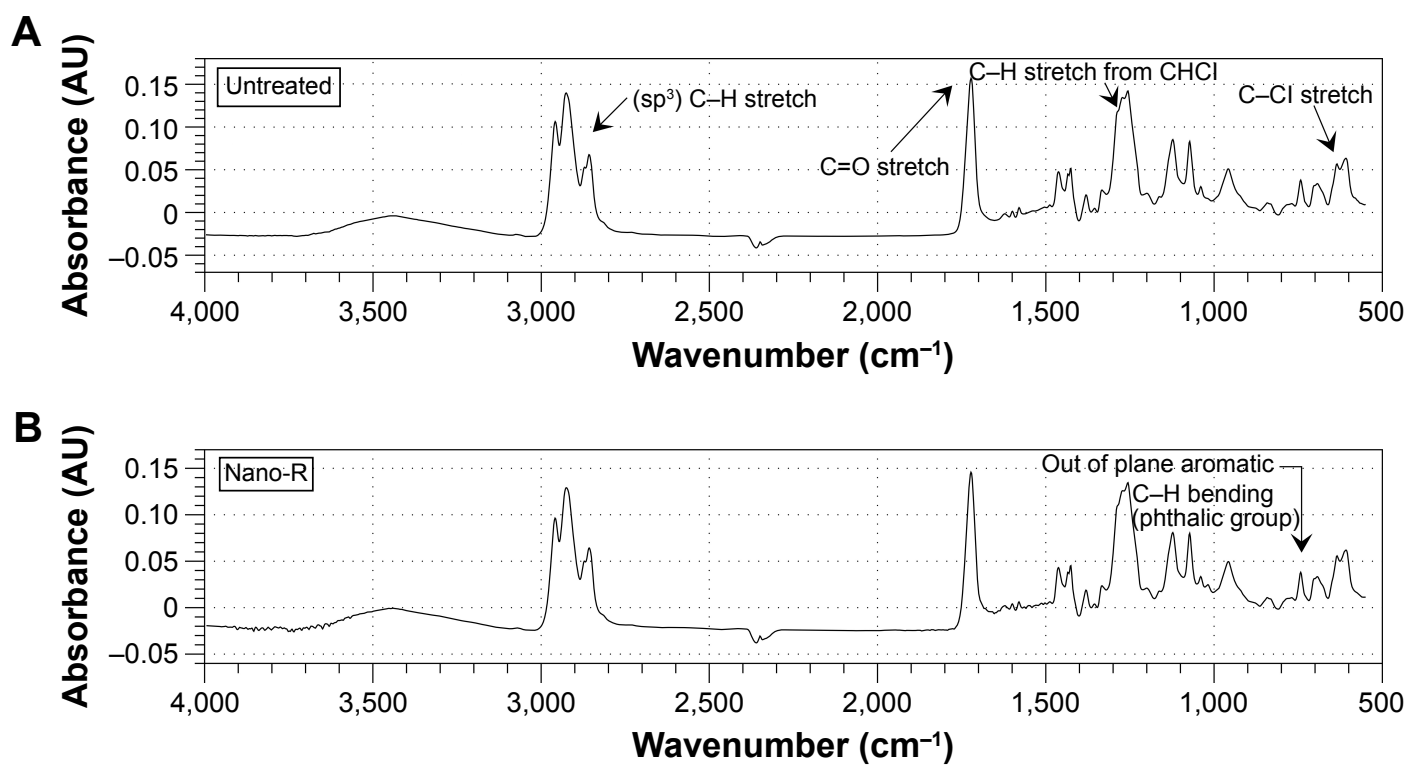

Figure 2 Fourier transform infrared spectroscopy spectra of the Sheridan ${ }^{\odot}$ polyvinyl chloride endotracheal tube $(\mathbf{A})$ untreated as compared to $(\mathbf{B})$ treated with a $0.1 \%$ Rhizopus arrhizus solution (nano-R). 
identified in the spectra by its principal absorption bands, the $\mathrm{C}-\mathrm{H}$ stretching bands at $2,800-3,000 \mathrm{~cm}^{-1}$ and the $\mathrm{C}-\mathrm{Cl}$ stretching vibrations near $600 \mathrm{~cm}^{-1} \cdot{ }^{21}$ Further characteristic PVC spectral bands within the fingerprint region were identified and compared to the literature. These include the wagging of the methylene groups at $1,427 \mathrm{~cm}^{-1}$, the stretching of $\mathrm{C}-\mathrm{H}$ from $\mathrm{Cl}-\mathrm{CH}$ at $1,257 \mathrm{~cm}^{-1}$, the $\mathrm{C}-\mathrm{C}$ bond of the backbone chain at $1,072 \mathrm{~cm}^{-1}$, and the rocking vibration of $\mathrm{CH}_{2}$ at $958 \mathrm{~cm}^{-1} \cdot{ }^{22}$

Additives, such as the phthalate plasticizer found in medical PVC, can also be identified from the FTIR spectra. The characteristic carbonyl band at $1,722 \mathrm{~cm}^{-1}$ is indicative of an aromatic ester as is the peak at $742 \mathrm{~cm}^{-1}$ indicating out of plane aromatic $\mathrm{C}-\mathrm{H}$ bending in a 1,2-disubstituted benzene ring (phthalic group). ${ }^{21,23} \mathrm{~A}$ peak corresponding to the symmetric stretching of the $\mathrm{C}-\mathrm{O}-\mathrm{C}$ grouping seen in aryl esters is also seen in the spectra of both the nanomodified and untreated samples at $1,124 \mathrm{~cm}^{-1} \cdot{ }^{21}$

A statistically significant correlation was found between the nanomodified PVC and the untreated surfaces (Pearson's correlation, $\left.R=0.997\left[R^{2}=0.994, P<0.001\right]\right)$, showing that no significant changes occurred between the nanomodified and untreated spectra. Small decreases in the intensity (0.01 absorbance units) of the $\left(\mathrm{sp}^{3}\right) \mathrm{C}-\mathrm{H}$ stretching bands, the $\mathrm{C}=\mathrm{O}$ stretch and the $\mathrm{C}-\mathrm{H}$ stretch were observed between the untreated and nano-R surfaces. A new absorbance band at $1,018 \mathrm{~cm}^{-1}$ could also be seen on the lipase-treated nano- $\mathrm{R}$ materials. This band has been shown to be associated with the stretching of the $\mathrm{C}-\mathrm{O}-\mathrm{H}$ bond and is thought to result from the degradation of the plasticizer. ${ }^{24}$

Figure 3 shows survey spectra from the XPS analysis of the ETT surface. The spectra of both nanomodified and untreated PVC samples contained peaks at C1s (286 eV), O1s (535 eV), and Cl2p3 (271 eV). As shown in Table 1, atomic percentages for carbon and chlorine differed from the values characteristic to pristine PVC (67 atomic\% C and 33 atomic\% $\%$ Cl). ${ }^{25}$ Both untreated tubes and nanomodified tube samples had an increased level of carbon (86 atomic\% and 75 atomic $\%$, respectively) at the surface of the tubes. In addition, oxygen was found on both surfaces (12.3 and 11.4 atomic\%). Si was also detected at the surface of the untreated PVC samples as seen in studies of other native PVC materials. ${ }^{26}$ The $\mathrm{O} / \mathrm{C}$ ratio was calculated from the survey spectra, for both the nano-R and untreated surfaces. This value showed a slight increase on all of the nano-R surfaces ( $0.14 \pm 0.02$ untreated to $0.15 \pm 0.01$ nano-R).

The XPS spectra of untreated and nanomodified samples soaked in TSB media for 24 hours were also analyzed.
A

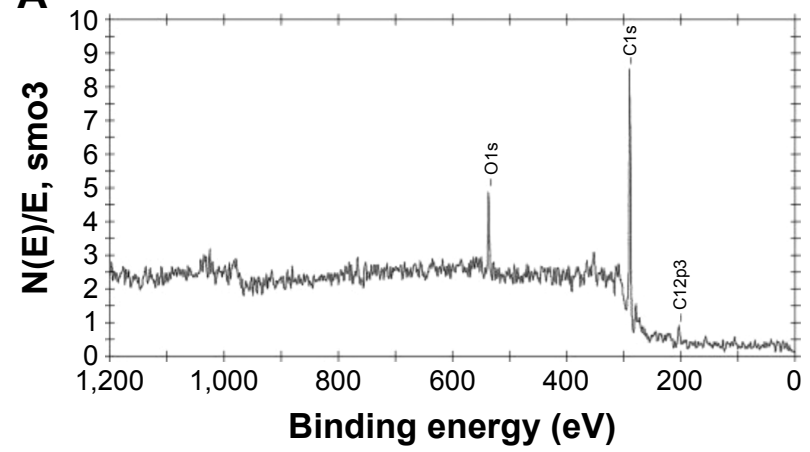

B

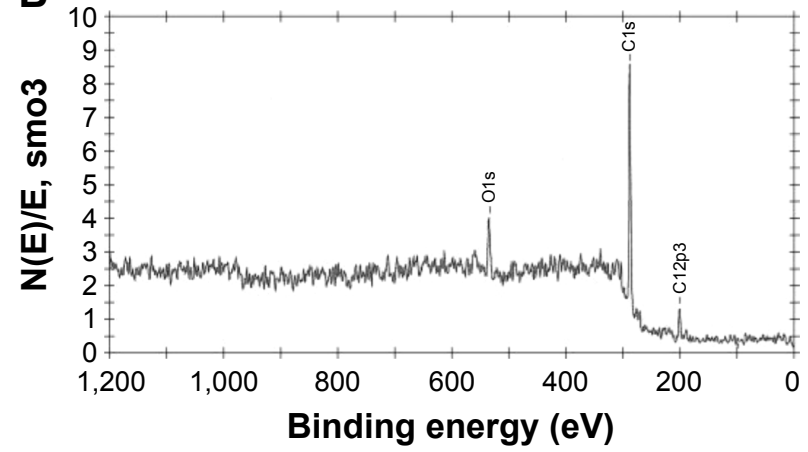

C

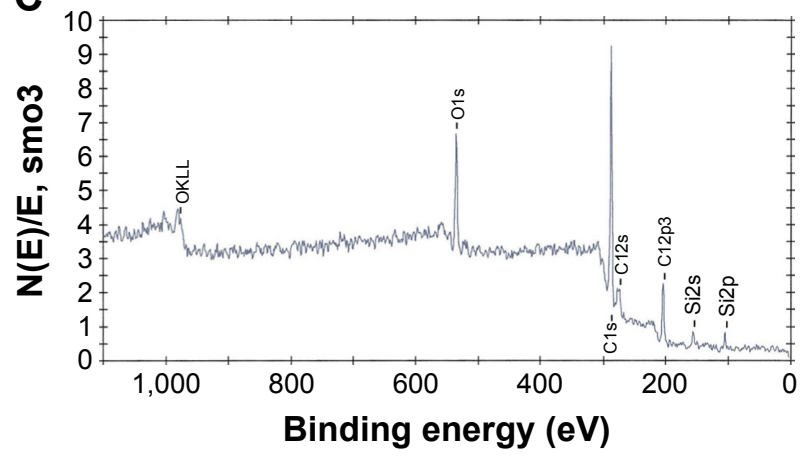

D

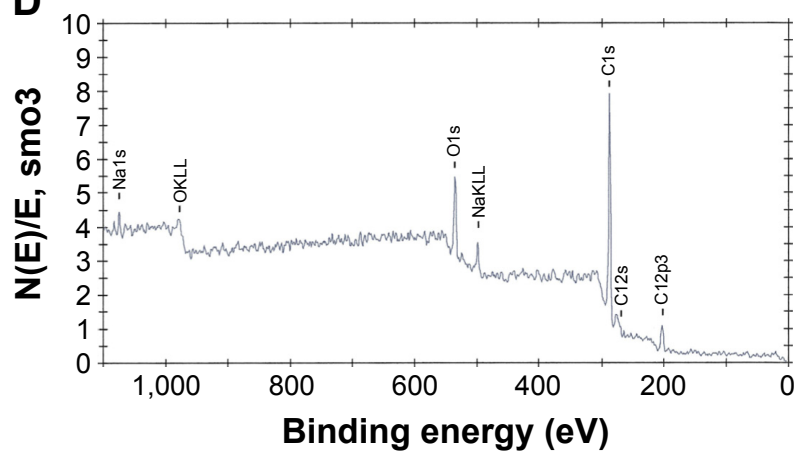

Figure 3 XPS survey spectra of the soaked Sheridan ${ }^{\odot}$ PVC ETT compared to previously reported spectra.

Notes: (A) Untreated as compared to ${ }^{10,27}$ (B) treated with a $0.1 \%$ Rhizopus arrhizus solution (nano-R). ${ }^{10,27}$ XPS spectra of Sheridan ${ }^{\odot}$ PVC ETT immersed in TSB for 24 hours (C) untreated as compared to (D) treated with a $0.1 \%$ R. arrhizus solution (nano-R).

Abbreviations: E, energy; ETT, endotracheal tube; N(E), number of emitted electrons as a function of energy; PVC, polyvinyl chloride; TSB, tryptic soy broth; XPS, X-ray photoelectron spectroscopy. 
Table I Atomic percentages of plasticized polyvinyl chloride endotracheal tube determined through $\mathrm{X}$-ray photoelectron spectroscopy analysis

\begin{tabular}{lllllll}
\hline & CIs & Ols & NaIs & Si2p & Cl2p & O/C \\
\hline Untreated & 86.1 & 12.3 & & & 1.7 & 0.14 \\
Nano-R & 75.1 & 11.4 & & & 7.9 & 0.15 \\
Untreated (24-hour TSB) & 76.8 & 11.1 & & 2.4 & 5.3 & 0.14 \\
Nano-R (24-hour TSB) & 84.5 & 10.4 & 1.5 & & 3.6 & 0.16 \\
\hline
\end{tabular}

Abbreviations: $\mathrm{Cls}$, carbon Is electron shell; OIs, oxygen Is electron shell; $\mathrm{Na}$ Is, sodium Is electron shell; Si2p, silicon 2p electron shell; Cl2p, chlorine 2p electron shell; O/C, oxygen to carbon ratio; Nano-R, $0.1 \%$ R. arrhizus solution; TSB, tryptic soy broth.

Untreated PVC samples soaked in TSB media for 24 hours had very similar surface chemistry to un-soaked surfaces. The XPS spectra of nanomodified ETT soaked in TSB media for 24 hours (Figure 3C and D) also included a peak at Na1s (atomic\% 3.59). This could be due to the adsorption of sodium ions from the media on the surface of the material after the degradation process. This adsorption of ions from media has been shown to affect many surfaces, and the adsorption of sodium ions from the culture media has been observed on the surface of many polymers, such as polyphenylacetylene ${ }^{27}$ This change in sodium adsorption supports our hypothesis that changes in nanoscale roughness alone can lead to changes in surface energy to influence ion adsorption important for bacteria functions.

\section{Discussion}

This study performed a detailed analysis of the surface chemistry of plasticized PVC ETT using both ATR-FTIR and XPS. No significant differences occurred between the spectra of the untreated and nanomodified pPVC in any region. In addition, analysis of the spectra of each region revealed that at most small, insignificant, differences in absorbance between the nanomodified and untreated spectra were not greater than or equal to the variance between the untreated samples. This suggests that no significant structural changes occurred in the surface chemistry of the nanomodified PVC ETT as a result of the 48-hour lipase treatment. Minor changes (0.008-0.01 absorbance units) were observed in the intensity of certain bands commonly associated with the plasticizer, including the $\left(\mathrm{sp}^{3}\right) \mathrm{C}-\mathrm{H}$ stretching bands, the $\mathrm{C}=\mathrm{O}$ stretch band, and the $\mathrm{C}-\mathrm{H}$ stretch band. No shifting or widening of the bands was observed in this spectra. These weak changes in the FTIR spectra are below the generally accepted limitation for significance in FTIR spectra, as they are less than three times the measured background noise (0.009-0.012 absorbance units). ${ }^{28}$ Although these minor changes at the surface of the nanoetched pPVC ETT material could indicate chemical changes that are below the limits of detection of
ATR-FTIR, it is unlikely that such changes significantly altered surface chemistry to influence the aforementioned decreased bacteria adhesion on nanoetched pPVC. Further spectroscopic studies of PVC modified with lipase at a range of concentrations $>0.1 \%$ could yield valuable insight into the mechanism of lipase degradation.

XPS analysis of the pPVC ETTs showed differences between this material and pristine PVC, including evidence of oxygen at the surface of the tubes and an increased concentration of carbon. This confirms the presence of plasticizer at the surface of these materials. Comparisons of the XPS data of nanomodified and untreated ETT showed a decrease of oxygen on the surface of the nano-R ETT, but indicated slight increases in the $\mathrm{O} / \mathrm{C}$ ratio on the nano- $\mathrm{R}$ samples. This further supports the proposed mechanism for the lipase etching process, suggesting that the release of plasticizer degradation products may cause restructuring of the ETT material surface. This, in turn, may influence the proportion of oxygenated functional groups at the surfaces of pPVC ETTs. ${ }^{24,29}$ The change is further supported by the increased hydrophilicity of the nano- $\mathrm{R}$ materials, as seen in previous studies. ${ }^{30,31}$ However, the $\mathrm{O} / \mathrm{C}$ ratio for these materials did not change significantly with the $0.1 \%$ lipase treatment suggesting that bacterial adhesion and growth on the surface of the nano- $\mathrm{R}$ material is influenced by other factors than surface chemistry.

Analysis of samples soaked in TSB culture media showed adsorption of sodium ions to the surface of these nanoetched materials. The adsorption of sodium ions from the media onto the surface of the nanoetched material suggests that the lipase nanoetching process may influence the surface energy of the nanomodified PVC, as a result of nanoscale surface features alone. The energy of the pPVC material may reduce bacterial adhesion at the surface as ionic materials have been shown to have lower initial adhesion than their nonionic counterparts. In fact, many natural surfaces are negatively charged. ${ }^{32}$

Charged polymer materials have complex electrostatic interactions with the surrounding media. The type of polymer surface, the concentration, and type of electrolyte, as well as the strain of bacteria can influence bacterial adhesion. ${ }^{33,34}$ Although small increases in electrolyte concentration have been shown to increase reversible bacteria adhesion at high electrolyte concentrations, electrostatic interactions between bacteria and the surface are reduced and bacteria adhesion is decreased. ${ }^{35,36}$ Marshall et al found that at a concentration of $\sim 5 \times 10^{-4} \mathrm{M}$ for $\mathrm{NaCl}$, Achromobacter were repulsed from the surface. ${ }^{37}$ Similar electrostatic repulsion of ocular bacteria such as $P$. aeruginosa was seen on hydrogel contact lenses immersed in high concentrations of $\mathrm{NaCl} .{ }^{38}$ Importantly, 
the change in surface energy on the nano-R pPVC ETT suggested by the adsorption of sodium ions to the surface of these materials may explain the significant decreases in bacteria function that occur on these nanomodified surfaces.

\section{Conclusions}

An XPS and ATR-FTIR characterization of nanoetched pPVC ETT assessed the chemical composition at the surface of these tubes and confirmed the presence of a plasticizer within this material. Qualitative and quantitative analyses of XPS and ATIR-FTIR showed that spectra from nanoetched pPVC ETT treated with a $0.1 \%$ lipase solution had no significant differences from the unetched pPVC. In addition, no shifting or widening of the bands was seen between the two materials. These results provide evidence that surfaces nanoetched with a $0.1 \%$ lipase solution for 48 hours have no significant change in surface chemistry and suggest that the unique antimicrobial properties of these materials are due to changes in the degree of the nanoscale roughness at the surface of the tubes, not changes in their surface chemistry.

\section{Acknowledgments}

The authors gratefully acknowledge the Hermann Foundation for providing the funding for this study. In addition, the authors would like to thank Keiko Tarquinio, Daniel Cheng, and Justin Seil for the scanning electron microscopy images and the XPS images included in this paper.

\section{Disclosure}

The authors report no conflicts of interest in this work.

\section{References}

1. Lovett PB, Flaxman A, Stürmann KM, Bijur P. The insecure airway: a comparison of knots and commercial devices for securing endotracheal tubes. BMC Emerg Med. 2006;6:7.

2. Elward AM, Warren DK, Fraser VJ. Ventilator-associated pneumonia in pediatric intensive care unit patients: risk factors and outcomes. Pediatrics. 2002;109(5):758-764.

3. Bigham MT, Amato R, Bondurrant $\mathrm{P}$, et al. Ventilator-associated pneumonia in the pediatric intensive care unit: characterizing the problem and implementing a sustainable solution. J Pediatr. 2009;154(4): 582.e2-587.e2.

4. Raymond J, Aujard Y. Nosocomial infections in pediatric patients: a European, Multicenter Prospective Study. Infect Control Hosp Epidemiol. 2000;21(4):260-263.

5. National Nosocomial Infections Surveillance System. National Nosocomial Infections Surveillance (NNIS) System Report, data summary from January 1992 through June 2004, issued October 2004. Am J Infect Control. 2004;32(8):470-485.

6. Srinivasan R, Asselin J, Gildengorin G, Wiener-Kronish J, Flori HR. A prospective study of ventilator-associated pneumonia in children. Pediatrics. 2009;123(4):1108-1115.

7. Warren DK, Shukla SJ, Olsen MA, et al. Outcome and attributable cost of ventilator-associated pneumonia among intensive care unit patients in a suburban medical center. Crit Care Med. 2003;31(5):1312-1317.
8. Brilli RJ, Sparling KW, Lake MR, et al. The business case for preventing ventilator-associated pneumonia in pediatric intensive care unit patients. Jt Comm J Qual Patient Saf. 2008;34(11):629-638.

9. Carraher CE. Additives and Starting Materials. In: Giant Molecules. Hoboken, NJ: John Wiley \& Sons, Inc.; 2003:435.

10. Sanvicens N, Marco MP. Multifunctional nanoparticles-properties and prospects for their use in human medicine. Trends Biotechnol. 2008; 26(8):425-433.

11. Kinnari TJ, Peltonen LI, Kuusela P, Kivilahti J, Könönen M, Jero J. Bacterial adherence to titanium surface coated with human serum albumin. Otol Neurotol. 2005;26(3):380-384.

12. Puckett SD, Taylor E, Raimondo T, Webster TJ. The relationship between the nanostructure of titanium surfaces and bacterial attachment. Biomaterials. 2010;31(4):706-713.

13. Ali MI, Ahmed S, Robson G, et al. Isolation and molecular characterization of polyvinyl chloride (PVC) plastic degrading fungal isolates. $J$ Basic Microbiol. 2014;54(1):18-27.

14. Webb JS, Nixon M, Eastwood IM, Greenhalgh M, Robson GD, Handley PS. Fungal colonization and biodeterioration of plasticized polyvinyl chloride. Appl Environ Microbiol. 2000;66(8): 3194-3200.

15. Gnanavel G, JayaValli M, Thirumarimurugan M, Kannadasan T. Degradation of plastics using microorganisms. IntJPharm Chem Sci.2012; 1(3):691-694.

16. Shah AA, Hasan F, Hameed A, Ahmed S. Biological degradation of plastics: a comprehensive review. Biotechnol Adv. 2008;26(3):246-265.

17. Stahl WH, Pessen H. The microbiological degradation of Plasticizers: I. Growth on Esters and Alcohols. Appl Microbiol. 1953;1(1):30-35.

18. Yang X, Wang B, Cui F, Tan T. Production of lipase by repeated batch fermentation with immobilized Rhizopus arrhizus. Process Biochem. 2005;40(6):2095-2103.

19. Mrozik A, Hupert-Kocurek K, Nowak B, Labuzek S. Microbial lipases and their significance in the protection of the environment. Post Mikrobiol. 2008;47:43-50.

20. Okamoto Y, Toda C, Ueda K, Hashizume K, Kojima N. Transesterification in the microbial degradation of phthalate esters. J Health Sci. 2011; 57(3):293-299.

21. Sigma Aldrich. Unit Definition: Lipase from Rhizopus Arrhizus. St. Louis, MO: Sigma Aldrich; 2010.

22. Young RJ, Lovell PA. Introduction to Polymers. 3rd ed. Boca Raton, FL: CRC Press; 2011.

23. Stromberg RR, Straus $S$, Achhammer BG. Infrared spectra of thermally degraded poly (vinyl chloride). J Res Natl Bur Stand. 1958;60(2):147.

24. Szöke S. 2 - normal co-ordinate analysis of benzene and its derivatives A2 - Varsányi, G. In: Vibrational Spectra of Benzene Derivatives. New York, NY: Academic Press; 1969:85-140.

25. Shashoua Y. Conservation of Plastics: Materials Science, Degradation and Preservation. Burlington, MA: Routledge; 2008.

26. Lemm W. The Reference Materials of the European Communities: Results of Hemocompatibility Tests. Springer science \& business media; 2013.

27. Focke WW, Radusch H-J. Engineering of Polymers and Chemical Complexity: New Approaches, Limitations and Control. Vol 2. Boca Raton, FL: CRC Press; 2014.

28. Iucci G, Rossi L, Rosato N, Savini I, Duranti G, Polzonetti G. The interaction of the polyphenylacetylene surface with biological environments studied by XPS, RAIRS and biological tests. J Mater Sci Mater Med. 2006;17(9):779-787.

29. Shrivastava A, Gupta VB. Methods for the determination of limit of detection and limit of quantitation of the analytical methods. Chron Young Sci. 2011;2(1):21-25.

30. Balazs D, Triandafillu K, Chevolot Y, et al. Surface modification of PVC endotracheal tubes by oxygen glow discharge to reduce bacterial adhesion. Surf Interface Anal. 2003;35(3):301-309.

31. Machado MC, Tarquinio KM, Webster TJ. Decreased Staphylococcus aureus biofilm formation on nanomodified endotracheal tubes: a dynamic airway model. Int J Nanomedicine. 2012;7:3741-3750. 
32. Seil JT, Rubien NM, Webster TJ, Tarquinio KM. Comparison of quantification methods illustrates reduced Pseudomonas aeruginosa activity on nanorough polyvinyl chloride. J Biomed Mater Res B Appl Biomater. 2011;98(1):1-7.

33. Van Loosdrecht M, Lyklema J, Norde W, Schraa G, Zehnder A. Electrophoretic mobility and hydrophobicity as a measured to predict the initial steps of bacterial adhesion. Appl Environ Microbiol. 1987; 53(8):1898-1901.

34. McEldowney S, Fletcher M. Adhesion of bacteria from mixed cell suspension to solid surfaces. Arch Microbiol. 1987;148(1):57-62.

35. Chapman GH. The significance of sodium chloride in studies of staphylococci. J Bacteriol. 1945;50(2):201-203.
36. Daeschel MA, McGuire J. Interrelationships between protein surface adsorption and bacterial adhesion. Biotechnol Genet Eng Rev. 1998; 15(1):413-438.

37. Marshall K, Stout R, Mitchell R. Mechanism of the initial events in the sorption of marine bacteria to surfaces. Microbiology. 1971;68(3): 337-348.

38. Cowell B, Willcox M, Schneider R. A relatively small change in sodium chloride concentration has a strong effect on adhesion of ocular bacteria to contact lenses. J Appl Microbiol. 1998;84(6):950-958.
International Journal of Nanomedicine

\section{Publish your work in this journal}

The International Journal of Nanomedicine is an international, peerreviewed journal focusing on the application of nanotechnology in diagnostics, therapeutics, and drug delivery systems throughout the biomedical field. This journal is indexed on PubMed Central, MedLine, CAS, SciSearch $®$, Current Contents $® /$ Clinical Medicine,

\section{Dovepress}

Journal Citation Reports/Science Edition, EMBase, Scopus and the Elsevier Bibliographic databases. The manuscript management system is completely online and includes a very quick and fair peer-review system, which is all easy to use. Visit http://www.dovepress.com/ testimonials.php to read real quotes from published authors.

Submit your manuscript here: http://www.dovepress.com/international-journal-of-nanomedicine-journal 